\title{
Letters
}

Website: www.bmj.com

Email: letters@bmj.com

\section{Consequences for research if use of anonymised patient data breaches confidentiality}

EDITOR-During this century well conducted clinical and epidemiological research has formed the basis of remarkable advances in medical knowledge. The benefits provided to countless patients by these advances have greatly outweighed the possible risks entailed in clinical studies. The success of these endeavours has been well safeguarded by established laws, directives, regulations, and guidelines. Research using patient records has provided important information on factors predisposing to disease and successful outcomes.

A recent legal case-Source Informatics (now owned by IMS Health) $v$ Department of Health, 28 May 1999-now threatens much healthcare research by suggesting that the use of patient data that have been subjected to procedures ensuring the anonymity of individual people may, nevertheless, constitute a breach of confidentiality. The consequences of this judgment are potentially so far reaching that the development of new treatments, particularly new drugs, may be seriously handicapped in the future. Studies that would be affected include individual case reports, retrospective

\section{Advice to authors}

We prefer to receive all responses electronically, sent either directly to our website or to the editorial office as email or on a disk. Processing your letter will be delayed unless it arrives in an electronic form.

We are now posting all direct submissions to our website within 24 hours of receipt and our intention is to post all other electronic submissions there as well. All responses will be eligible for publication in the paper journal.

Responses should be under 400 words and relate to articles published in the preceding month. They should include $\leqslant 5$ references, in the Vancouver style, including one to the BMJ article to which they relate. We welcome illustrations.

Please supply each author's current appointment and full address, and a phone or fax number or email address for the corresponding author. We ask authors to declare any competing interest. Please send a stamped addressed envelope if you would like to know whether your letter has been accepted or rejected.

Letters will be edited and may be shortened.

www.bmj.com

letters@bmj.com archival research, the use of tissue samples, some case-control studies, observational cohort studies, prescription based investigations, and studies using computerised databases of medical records.

The unique value of this research is that it can provide information that is inaccessible to randomised, controlled clinical trials, which require ethical approval and informed patient consent because they are prospective and experimental. These requirements greatly reduce the inclusion of young children, pregnant women, very old and very sick people, and those unable to give informed consent. However, medical practice includes a high proportion of such patients who are underrepresented or excluded from clinical trials. Furthermore, as has been reported by Rawlins and Jeffreys, ${ }^{1}$ considerations of feasibility and cost often limit the numbers of patients exposed to a drug to a maximum of a few thousand for comparatively short times. Computerised databases in primary care can extend times to many years of continuous care and the numbers of patients to millions; this would be impossible to do in any other way.

The judge in the recent legal case recognised that, in certain circumstances, the benefits derived from anonymised patient data might outweigh any problems of confidentiality but also raised the concept that this would not be an acceptable exemption if the purpose(s) for which the data were intended were to be classified as "commercial." Uncertainties about the precise meaning of this term raise further doubts about using anonymised patient data in research, particularly as some of the studies we envisage might be regarded as market research into the effective use of new drugs.

We strongly support the acceptability of using anonymised patient data for healthcare research without this being regarded as a breach of confidentiality. We agree that ethical scrutiny of specific study plans is generally desirable but that informed consent is both unnecessary and often impractical. The purpose(s) for which a study is conducted should be clearly stated but would not be disallowed on the grounds that certain aspects could be described as commercial or relating to commerce.

We recommend that written guidelines, such as those proposed by a working group of the Royal College of Physicians, ${ }^{2}$ be used to clarify the current uncertain situation. Any measures that would restrict noninterventional, observational research on unidentifiable patients by the setting up of unnecessary and impractical requirements will inevitably have deleterious effects on progress in health care.

Walton of Detchant, Lord former warden, Green College, Oxford

Oxford OX2 6PS

Richard Doll director, Clinical Trials Service Unit Clinical Trials Service Unit and Epidemiological Studies Unit, Nuffield Department of Clinical

Medicine, University of Oxford, Radcliffe Infirmary, Oxford OX2 6HE

William Asscher former chairman, Committee on Safety of Medicines

Llangen, Near Bridgend, Vale of Glamorgan

Rosalinde Hurley former chairman,

Medicines Commission

Harold Wood, Essex RM3 0LJ

Michael Langman professor of medicine Department of Medicine, University of Birmingham Queen Elizabeth Hospital, Birmingham B15 2TH

Raanan Gillon medical ethicist

Ethics Unit, Imperial College Health Centre, London SW7 ILU

David Strachan professor of public health sciences Department of Public Health Sciences, St George's Hospital Medical School, London SW17 0RE

Nicholas Wald professor of environmental and preventive medicine

Department of Environmental and Preventive Medicine, St Bartholomew's Hospital Medical College, London EC1A 7BE

Peter Fletcher independent consultant Pharma Services International, The Mill, Stortford Road, Hatfield Heath, Near Bishop's Stortford, Hertfordshire CM22 7DI

(Corresponding author)

1 Rawlins MD, Jeffreys DB. Study of United Kingdom product licence applications containing new active substances. BMJ 1991;302:322-5.

2 Royal College of Physicians Committee on Ethical Issues in Medicine. Research based on archived information and samples. J R Coll Physicians Lond 1999;33:264-6.

\section{Discontinuation of ventilation after brain stem death}

\section{Asystole rapidly follows brain stem death}

Editor-We were interested in the educational debate concerning withdrawal of ventilatory support after confirmation of brain stem death. ${ }^{1}$ Clearly if ventilatory support is withdrawn without the agreement of the family, although such action may be medically and legally correct, the potential for sensationalised unfavourable headings in tabloid newspapers must be considered.

Although the medicolegal and ethical aspects of the issue have been discussed, the 
scientific aspects have not been. Unlike in the persistent vegetative state, brain stem death is followed by a series of profound changes in the autonomic and hormonal mechanisms regulating the cardiovascular system. Complete cardiovascular and autonomic uncoupling has been shown in humans after brain stem death. ${ }^{2}$ In validated animal models of brain stem death a catecholamine surge was consistently observed after brain stem death, followed rapidly by decreases in vasopressin, adrenocorticotrophic hormone, thyroxine, and glucagon concentrations. ${ }^{3}$ Inotropic and vasoactive treatment is therefore frequently required to maintain organ function for potential donation

It has been established that, despite full cardiovascular support, most deeply comatose patients ( $97 \%$ of 140$)$ will develop asystole in a week. ${ }^{4}$ Clearly, the time for developing asystole is likely to be shorter in patients with brain stem death, especially if full cardiovascular support is not attempted. We suggest that in such cases it would be reasonable to continue ventilatory and circulatory support without further manipulation. In almost all cases managed in this way rapid cardiac death will ensue.

Although we have no satisfactory answer to the central question raised as to whom the duty of care is greatest-the grieving family or another critically ill patient-we believe that nature should be allowed to take its own course and end the dilemma.

$\mathbf{R}$ Khanna specialist registrar, accident and emergency department

Walsall Manor Hospital, Walsall WS2 9PS

M A Chaudhry specialist registrar, accident and emergency department

Birmingham Heartlands Hospital, Birmingham B9 5SS

mehmood.chaudhry@talk21.com

1 Swinburn JMA, Ali SM, Banerjee DJ, Khan ZP, Cranford RE, Jennett B. Ethical dilemma: Discontinuation of ventilation after brain stem death. BMJ 1999;318:1753-5. (26 June.)

2 Goldstein B, Toweil D, Lai S, Sonnenthal K, Kimberly B. Uncoupling of the autonomic and cardiovascular systems in acute brain injury. Am J Physiol 1998;275:1287-92.

3 Chen EP, Bittner HB, Kendall SW, Van Trigt P. Hormonal and hemodynamic changes in a validated animal model of brain death. Crit Care Med 1996;24:1352-9.

4 Hung TP, Chen ST. Prognosis of deeply comatose patients on ventilators. J Neurol Neurosurg Psychiatry 1995;58:75-80.

\section{Jews accept brain stem death}

EDITOR-The issue of brain stem death ${ }^{1}$ became important in Israel in the 1980s, when heart and liver transplantation began. Many people objected to organ donations in "beating heart" situations, fearing conflict with the religious Halachic law.

In 1986 the chief rabbinate of Israel responded to an approach from me (as the then director general of the Ministry of Health) and Professor Abraham Sahar, a neurosurgeon, to accept brain stem death as religiously acceptable for $(a)$ pronouncing death and $(b)$ obtaining permission for harvesting organs from donors. There were two points we asked them to consider.

The first point was the rule that "Breathing is equivalent to soul." In Hebrew the word neshama is from the same root as neshima; while the first means "soul" the second means "respiration." One saying is "haneshama hee hanefesh" ("haneshama is the soul." In this case neshama also means "breathing." The second point relates to the saying that one should not stop the neshama from leaving the body (when the time comes). Therefore we maintained that when spontaneous respiration does not exist, a state of death has been reached and at this point we should not, in the Halachic sense, continue artificial respiration, which prevents the soul from leaving the body. In this situation we maintained that it should be permissible to harvest organs of the dead person that may preserve the life and health of another.

The chief rabbinate had about eight months of internal deliberations before they accepted this formula. Since that time in Israel the official Jewish religious authorities have accepted brain stem death for the declaration of death and for approaching families to accept donation of organs for transplantation.

Dan Michaeli chairman, board of directors Kupat Holim Clalit, Tel Aviv 62098, Israe michaeli@netvision.net.il

\section{Swinburn JMA, Ali SM, Banerjee DJ, Khan ZP, Cranford RE, Jennett B. Ethical dilemma: Discontinuation of ventilation after brain stem death. BMJ 1999;3 18:1753-5. (26 June.)}

\section{Criticisms of Swedish mammography trials were wrong}

EditoR-In their attempt to answer Rosén and Rehnqvist's criticism of their study, Sjönell and Ståhle inaccurately attack the Swedish randomised trials of breast cancer screening and in particular the two county study. ${ }^{2}$ They allege that the control group was invited to screening and that this was contrary to the trial protocol. In fact, the protocol stated that the control group was to be kept free of screening for at least five years but that it would be unethical to withhold screening after a significant mortality benefit had been shown. The two county study adhered to both of these conditions.

At the time of the first definitive publication of the results in $1985^{3}$ only $13 \%$ of the control group had been exposed to mammographic examination-that is, $87 \%$ of the controls were completely unexposed to mammography. Without this contamination of the control group our observed benefit would be even larger than the 30\% reduction in mortality obtained. What is clear is that Sjönell and Ståhle's allegation that screening of the control group somehow caused an artificial benefit can now be seen to be ridiculous. If Sjönell and Ståhle are asserting that screening confers an excess mortality we should be grateful if they would explain the mechanism whereby such an excess in 13\% of the control group would be sufficient to outweigh the same excess in around $90 \%$ (the approximate attendance rate) in the study group.
We find offensive the insinuation that we concealed the screening of the control group in any way. The 13\% contamination was reported with the first definitive results. ${ }^{3}$ The policy of offering screening to the control group once a significant mortality benefit had been shown-which is in line with good ethical practice in randomised trials - was a condition for starting the trial. It has been common knowledge among the Swedish medical community and indeed the population for around two decades. The fact that Sjönell and Ståhle have only just become aware of it speaks for itself.

Laszlo Tabar director

Mammography Department, Central Hospital, 97182 Falun, Sweden

Stephen W Duffy senior scientist

MRC Biostatistics Unit, Institute of Public Health, Cambridge CB2 2SR

stephen.duffy@mrc-bsu.cam.ac.uk

1 Rosén M, Rehnqvist N. Breast screening. BMJ 1999;318: 809-10. (20 March.)

2 Sjönell O, Ståhle L. Scientific foundation of mammographic screening is based on inconclusive research in Sweden. BMJ 1999:319:55. (3 Julv.)

3 Tabar L, Fagerberg CJG, Gad A, Baldetorp L, Holmberg $\mathrm{LH}$, Gröntoft $\mathrm{O}$, et al. Reduction in mortality from breast cancer after mass screening with mammography Lancet $1985 ; \mathrm{i}: 829-32$

\section{Sexual health of teenagers}

\section{Trends should be examined over longer} period

EDITOR-Nicoll and colleagues report large percentage increases between 1995 and 1996 in indicators of sexual health in English teenagers. ${ }^{1}$ This is clearly of concern given the potential for serious health and social consequences. But it is important to look at trends in these various indicators over a longer period in order to obtain an accurate picture and to be aware of the impact on these of other, sometimes transient, factors.

Scottish publications routinely include data on teenage sexual health. ${ }^{2-4}$ We have examined the trends in indicators of sexual health among Scottish teenagers between 1993 and 1997 in some detail. The only indicators which convincingly show an increasing trend between 1993 and 1997 are genital chlamydia and genital warts in females; the data on pregnancies are less convincing (figure).

There are several factors which contribute to the increasing trend, including increased "unsafe sex." Nicoll and colleagues point out that increased attendance by teenagers at genitourinary medicine clinics may have contributed to the increased rates of diagnosis of gonorrhoea and genital chlamydia in these clinics. They also refer to the importance of gonorrhoea in young men who have sex with men within the total infections in teenagers. Increased awareness and the introduction of more sensitive methods of diagnosis of Chlamydia trachomatis infection in recent years has led to increased screening and diagnosis of this largely asymptomatic infection in teenagers, among whom the highest prevalence of infection is found. 


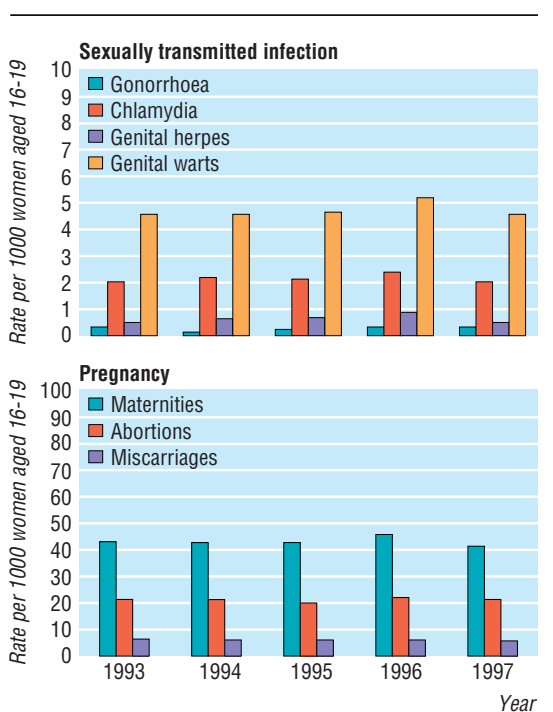

Rates of sexually transmitted infections (top) and pregnancy (bottom) in women in Scotland aged 16-19 years

There are also data to indicate that the "pill scare" in 1995 led to increased conception and termination rates among teenagers in the first two quarters of $1996 .{ }^{5}$

Our data do not negate the need to ensure that appropriate and effective health promotion approaches are in place as each new generation reaches the teenage years. We also need to be aware of events which may affect trends in indicators of sexual health and to interpret the data with care.

Ahilya Noone consultant epidemiologist Scottish Centre for Infection and Environmental Health, Clifton House, Clifton Place, Glasgow G3 7LN

ahilya.noone@scieh.csa.scot.nhs.uk

Jim Chalmers consultant in public health medicine Mark Hollinsworth statistical support manager Kenny McIntyre administrative and technical support officer

Beatrice Cant senior health information scientist Information and Statistics Division, NHS in Scotland, Edinburgh, Scotland

1 Nicoll A, Catchpole M, Cliffe S, Hughes G, Simms I, Thomas D. Sexual health of teenagers in England and Wales: analysis of national data. BMJ 1999;318:1321-3. (15 June.)

2 Information and Statistics Division. Teenage pregnancy in Scotland-a fifteen year review, 1983-1997. Health briefing. Edinburgh: ISD, 1998.

3 Information and Statistics Division. Scottish health statistics 1998. Edinburgh: ISD,1999.

4 Information and Statistics Division. Genitourinary medicine statistics Scotland-year ending 31 March 1998. Edinburgh:
s.tione statistics Sco

5 Wood R, Botting B, Dunnell K. Trends in conception before and after the 1995 pill scare. Popul Trends 1997 Autumn:5-12

\section{Time to put it in perspective}

EDITOR-Nicoll et al's paper on sexual health in England and Wales again gives the impression that the sexual health of teenagers is getting worse. ${ }^{1}$ Until I started research on this subject I, like the majority of the British population, thought that the rate of teenage pregnancy was escalating out of sight. In fact this is not the case. Yes, we do have the highest rate in western Europe, but it is decreasing from much higher rates in the past.
In 1969 there were 117304 conceptions in the age group 16-19 years in England and Wales and only $8 \%$ of these were terminated under the new law. This compares with 59612 births and 34752 terminations of pregnancy (total 94364 ) in 1996. The number of live births in 1996 was only $55 \%$ of that in 1968, mainly because over a third of pregnancies in women of this age group are now terminated.

There is obviously concern that the conception rate for teenagers rose from 1995 to 1996 , but this does coincide with the much regretted and disastrously handled pill scare and a rise in all age groups was seen at this time. It is misleading to look at just two years and not at the bigger picture. This is elegantly done by a more recent paper, which placed rates of conception in their historical context and showed that although teenage sexual activity is increasing the trend in fertility is generally downwards.

This is not to underestimate the effect of teenage pregnancy nor of its concern to our society, but it should be put in perspective. England and Wales have always had high rates of teenage pregnancy and there may be many reasons for this. However, we are now seeing lower rates despite the likelihood that women are experiencing sexual intercourse at an earlier age. ${ }^{4}$ This should be seen as an achievement on which to build, and we should be sending a more positive message to health professionals, sex education workers, and above all adolescents.

Clare J Seamark general practitioner

Honiton Group Practice, Honiton, Devon

EX14 2NY

daseamark@msn.com

1 Nicoll A, Catchpole M, Cliffe S, Hughes G, Simms I, Thomas D. Sexual health of teenagers in England and Wales: analysis of national data. BMJ 1999;318:1321-2 (15 June.)

(15 June.)

Office of Population Censuses and Surveys. Birth statistics. London: HMSO 1969-92. (FM1)

3 Wellings K, Kane R. Trends in teenage pregnancy in England and Wales: how can we explain them? J R Soc Med 1999;92:277-82

4 Wellings K, Field J, Johnson A, Wadsworth J. Sexual behav

iour in Britain. Harmondsworth: Penguin, 1994.

\section{Comprehensive youth clinics are needed}

EDITOR-The paper by Nicoll et $\mathrm{al}^{1}$ and other recent statistics show no reduction in teenage pregnancies or risk taking and an increased incidence of sexually transmitted diseases, cervical intraepithelial neoplasia, ectopic pregnancy, and tubal infertility despite extensive sex education programmes and the expenditure of large sums on medical and social services. Where have we gone wrong?

Firstly, we have assumed that sex education can be undertaken by teachers, often inadequately trained and hampered by barriers created by the existing pupilteacher relationship. Many feel uncomfortable and diffident about discussing issues such as masturbation, homosexuality, rape, and abortion. Secondly, we have not acknowledged that many general practitioners lack the time, experience, or facilities needed to run a comprehensive adolescent service. Difficulties with appointment systems and anxiety about confidentiality can pose further problems. Thirdly, we have ignored the fact that many adolescents are already sexually active (and often pregnant) when they first approach their doctor or a Brook clinic. The overwhelming need is to establish a bridge between sex education and the provision of medical services so that adolescents know where to go for advice before they start a sexual relationship.

Since the early 1970s youth clinics have been functioning in towns throughout Sweden. The clinic doctors and nurses join in sex education programmes at the local schools. Adolescents are educated and counselled before they become sexually active. They are specifically encouraged to attend the youth clinic before embarking on a relationship. When they do, they meet familiar staff who taught them at school and who provide a welcoming clinical service with advice on sexuality, interpersonal relationships, contraception, and avoidance of sexually transmitted diseases. Contraception, termination, diagnosis and treatment of lower genital tract infections, cervical cytology, and contact tracing are available. In the United Kingdom such services are fragmented and dealt with by a variety of specialists and clinics.

In Sweden the introduction of youth clinics has led to a significant reduction in the incidence of teenage pregnancies, terminations, gonococcal and chlamydial infections, pelvic inflammatory disease, and ectopic pregnancy. Pilot studies should be set up in Britain with youth clinics staffed by doctors and nurses with special training, interest, and experience in sex education, contraception, gynaecology, and urogenital medicine.

The issues are measurable: sexual activity in different age groups and the incidence of risk taking, pregnancy, abortion, and sexually transmitted disease. The cost of such a programme will be small compared with that of the present laissez-faire approach to adolescent sexual health.

Herbert E Reiss retired consultant gynaecologist Harlton, Cambridge CB3 7ET

1 Nicoll A, Catchpole M, Cliffe S, Hughes G, Simms I, Thomas D. Sexual health of teenagers in England and Wales: analysis of national data. BMJ 1999;318:1321-3. (15 June.)

\section{Authors' reply}

Editor-Noone et al demonstrate important differences in the epidemiologies of sexually transmitted diseases and teenage births and terminations in the United Kingdom. From 1993 to 1997 diagnoses of gonorrhoea, genital chlamydia, and genital warts among teenagers aged 16-19 years reported by English genitourinary medicine clinics all rose significantly. ${ }^{1}$ Scottish clinics experienced no rise in gonorrhoea and much smaller rises in chlamydia and warts. Similarly, we found that teenage births rose in England and Wales but not in Scotland. So there are differences between England and Scotland, but equally there are important differences between regions within England. ${ }^{1}$ England's rise in gonorrhoea, the 


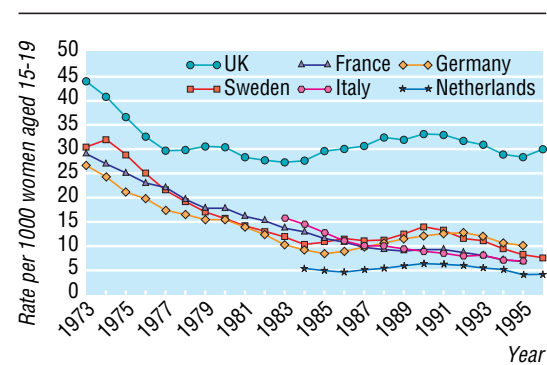

Live birth rate for women aged 15-19 in European countries, 1973-96. ${ }^{3}$ Rates are based on maternal age at end of reporting year in France, Germany, Netherlands, and Sweden

sexually transmitted disease considered most sensitive to behavioural changes, occurred from 1994 to 1997 (it ceased in 1998) across all age groups and both sexes and included male homosexuals. This rise differed considerably from the rise in the late 1980 s, which was mostly confined to homosexual males in London. However, it did not occur in every English region and the reasons for this require elucidation.

Seamark points out that conceptions among teenagers in England and Wales have declined since the 1970s even though the average age of sexual debut has fallen over this period. However, Britain has done poorly compared with mainland Europe, where age of sexual debut has also fallen but teenage birth rates have fallen far more (figure). ${ }^{2}{ }^{2}$ Both Noone and Seamark repeat the commonly held view that a rise in births and terminations in England and Wales in 1996 was due to the "pill scare" of 1995 (when concern was expressed over the safety of taking oral contraceptives). This undoubtedly contributed to the rise, but another plausible contributor was whatever behavioural changes underlied the increases in gonorrhoea. A decline in use of oral contraceptives should result in falling incidence of bacterial sexually transmitted disease as some couples adopt barrier contraception. In fact the opposite occurred, and it is striking that Noone et al report neither a "pill scare" effect on births and terminations nor a rise in gonorrhoea in Scotland.

Our article was misreported in the popular press as stating that sexual behaviour in teenagers was worsening. We made no comment on behaviour, data on which will have to wait the results of the current second national survey of sexual attitudes and lifestyles. Rather we pointed out the heavy and perhaps increasing burden of sexual ill health in teenagers in England and Wales. The case for integrated policies preventing, detecting, and treating sexual ill health remains as strong as ever. ${ }^{4}$

Angus Nicoll consultant epidemiologist ANicoll@phls.nhs.uk

Mike Catchpole consultant epidemiologist HIV and Sexually Transmitted Disease Division, Public Health Laboratory Service Communicable Disease Surveillance Centre, London NW9 5EQ

1 Hughes G, Simms I, Rogers PA, Swan AV, Catchpole M. New cases seen at genitourinary medicine clinics: England 1997. Commun Dis Pub Health 1998;(suppl).
2 Boxon M, Kontula O. Sexual initiation and gender in Europe: a cross-cultural analysis of trends in the twentieth century. In: Hubert M, Bajos N, Sandford J, eds. Sexual behaviour and HIV/AIDS in Europe. Comparisons of national surveys. London: UCL Press, 1998:37-67.

3 Council of Europe. Recent demographic developments in Europe. Strasbourg: Council of Europe, 1997.

4 Department of Health. First ever government strategy on sexual health launched. Press release, 23 March. London: $\mathrm{DoH}$ 1999. $(1999 / 0166$.

\section{Royal Medical Benevolent Fund reminds readers of its Christmas appeal}

Editor-The season of Christmas is here. Irrespective of race or creed we all look forward to one of the happiest times of the year-but not for everyone. Those of us connected with the Royal Medical Benevolent Fund know only too well the sadness that follows unexpected tragedy within our profession. The hardship that may follow seems magnified at this time of year-all the more so when young children are affected.

The generosity of $B M J$ readers last Christmas enabled the Royal Medical Benevolent Fund to distribute additional seasonal support of $£ 50000$ to help bring some semblance of happiness and dignity to doctors less fortunate than themselves, and particularly their bereaved families. Each year the general grants of the fund total over $£ 800000$.

The fund always seeks to give this extra help at Christmas with gifts to the children concerned. May I therefore ask for your support again this year?

Contributions marked Christmas appeal may be sent to the chief executive officer at this address or to the treasurers of local guilds of the fund. Thank you.

Rodney Sweetnam president

Royal Medical Benevolent Fund, 24 King's Road, London SW19 8QN

\section{Reducing the risk of major elective surgery}

\section{Paper should have given details on causes} of death

Editor-Does the result of Wilson et al's trial from a district general hospital justify routine preoperative administration of inotropes and fluids to all patients having major elective surgery? ${ }^{1}$ Detailed mortality data, in particular on the cause of death, are lacking in their results, surprisingly. The morbidity data show that there was a significantly increased rate of surgical complications in the control group compared with the study group (seven of the 46 patients in the control group developed surgical complications (four cases of anastomotic breakdown and three of deep haemorrhage) compared with four of the 92 in the study group (all cases of deep haemorrhage); $\mathrm{P}=0.04$ ).

If any of these surgical complications were the direct cause of death in the controls then the effectiveness of the preoperative regimen in the study group in reducing mortality becomes ambiguous. This would be particularly pertinent with regard to the two late deaths in the control group, since these deaths are unlikely to have been due to inadequate preoperative optimisation of oxygen delivery. The use of $4.5 \%$ albumin and of red cell transfusion below a blanket threshold haemoglobin concentration of $110 \mathrm{~g} / \mathrm{l}$ is a controversial issue..$^{2-4}$

S Sudhindran specialist registrar

Royal Liverpool University Hospital, Liverpool L7 8XP

sudhindran@bigfoot.com

1 Wilson J, Woods I, Fawcett J, Whall R, Dibb W, Morris C, et al. Reducing the risk of major elective surgery: randomised controlled trial of preoperative optimisation of oxygen therapy. BMJ 1999:7191:1099-103.(24 April) 2 Cochrane Injuries Group Albumin Reviewers. Aril.) Cochrane Injuries Group Albumin Reviewers. Human albumin administration in critically ill patients: systematic review $235-40$.

3 Hebert PC, Wells G, Blajchman MA, Marshall J, Martin C, Hebert PC, Wells G, Blajchman MA, Marshall J, Martin C,
Pagliarello G, et al. A multicenter, randomized, controlled Pagliarello G, et al. A multicenter, randomized, controlled
clinical trial of transfusion requirements in critical care. $N$ clinical trial of transfusion re

Engl JMed 1999;340:409-17.

4 Schierhout G, Roberts I. Fluid resuscitation with colloid or crystalloid solutions in critically ill patients: a systematic review of randomised trials. BMJ 1998;316:961-4.

\section{Better management of intensive care unit} beds is necessary

EDITOR-Wilson et al's randomised controlled trial in high risk surgical patients goes some way to showing the benefits of intensive care ${ }^{1}-$ a service hopelessly underfunded and therefore underused in the United Kingdom. This low priority in the United Kingdom is highlighted yet again in the study, by the 16 patients in the control group who did not receive intensive or high dependency care immediately after their high risk surgery despite beds being available.

It is hard to know if the small heterogeneous groups in the study were matched for severity of illness, skill of the surgeon and anaesthetist, and volume of blood transfused. All of these factors can have a considerable impact on mortality and morbidity, ${ }^{23}$ and the POSSUM score is only a very crude means of assessing the degree of matching. Certainly, the trend for an increased incidence of a history of ischaemic heart disease and the absence of haemodynamic data in the control patients make it difficult to know if the groups were matched for cardiac function.

The absence of control haemodynamic measurements also makes it impossible to be sure that it was the cardiovascular manipulation alone rather than intensive care that improved outcome. How many treated patients in either group reached the oxygen delivery target of $600 \mathrm{ml} / \mathrm{min} / \mathrm{m}^{2}$ with fluid by itself? Table 2 suggests that this occurred more commonly in the dopexamine group, cardiovascular function being better preserved in these patients. In the past this has been associated with an improved prognosis. ${ }^{4}$ The study design, which required all treated patients to receive a vasoactive drug whatever their oxygen delivery, makes it impossible to provide any plausible mechanism by which dopexamine could have been so much more effective than low doses of adrenaline. 
Of greatest concern is the mortality in the control group of $17 \%$; optimisation that required the regular use of pulmonary artery catheterisation and vasoactive drugs reduced mortality to $3 \%$. A different healthcare system with three times as many intensive care unit beds, in which a quarter of admissions to the intensive care unit are of patients who have had elective surgery (versus 5\% in the United Kingdom) can achieve a $5 \%$ hospital mortality in elective surgical patients in our tertiary referral hospitals without the paraphernalia (and risks) of optimisation. This suggests that the factor improving outcome is not so much the perioperative targeting of oxygen delivery or the administration of dopexamine but the overall package that comes with proper intensive care management.

Imogen Mitchell staff specialist in intensive care Royal Prince Alfred Hospital, Camperdown, Sydney, Australia

David Bihari associate professor of critical care medicine

University of New South Wales, St George Hospital, Kogarah, Sydney

d.bihari@unsw.edu.au

1 Wilson J, Woods I, Fawcett J, Whall R, Dibb W, Morris C, et al. Reducing the risk of major elective surgery: randomised controlled trial of preoperative optimisation of oxygen delivery. BMJ 1999;318:1099-103. (24 April.)

2 Houghton A. Variation in outcome of surgical procedures. Houghton A. Variation in
BrJ Surg 1994;81:653-60.

3 Hebert PC, Wells G, Blajchman MA, Marshall J, Martin C, Pagliarello G, et al. A multicenter, randomized, controlled clinical trial of transfusion requirements in critical care. $N$ Engl J Med 1999;340:409-17.

4 Hayes MA, Timmins AC, Yau EH, Palazzo M, Hinds CJ, Watson D. Elevation of systemic oxygen delivery in the treatment of critically ill patients. $N$ Engl $J \mathrm{Med}$ 1994;330:1717-22

5 Pronovost PI, Jenckes MW, Dorman T, Garrett E, Breslow MJ, Rosenfeld BA, et al. Organizational characteristics of intensive care units related to outcomes of abdominal aortic surgery. JAMA 1999;281:1310-7.

\section{These results must now be put into clinical practice}

EDITOR-Wilson et al used fluid replacement and inotrope therapy to optimise the circulation in order to increase tissue oxygen delivery to a predetermined goal; this resulted in a reduction in mortality in patients undergoing major elective surgery. ${ }^{1}$ Three years previously the Multicenter Study of Perioperative Ischemia Research Group reported a study in which perioperative $\beta$ blockade (continued for the duration of stay in hospital) reduced perioperative ischaemia, infarction, and two year mortality in patients undergoing similar types of surgery. ${ }^{2}$

Comparison of the patients in both studies shows clear similarities. At least 119 $(86 \%)$ of the 138 patients in Wilson et al's study would have been eligible for the research group's study, these being patients with or at risk of ischaemic heart disease. Both studies had relatively few patients with congestive heart failure (study by Multicenter Study of Perioperative Ischemia Research Group 8\%; Wilson et al's study $6 \%)$. So how can both inotrope therapy and $\beta$ blockade-two apparently contradictory treatment strategies-improve outcome in similar patients?
The goal of perioperative management must be to maintain or enhance cardiac output while protecting against myocardial oxygen imbalance. The key to this goal is effective preparation and monitoring. Outside the artificial constraints of clinical trials, various other treatments (for example, fluids, vasodilators, $\beta$ blockers, and inotropes) may be needed but treatment must be guided by data, not dogma.

In Wilson et al's paper the importance of fluid loading is obvious from the data and acknowledged by the authors. ${ }^{1}$ The value of inotrope therapy is less clear, and the choice of agent may be important. The splanchnic vasodilator effects of dopexamine mediated by dopaminergic DA1 receptor agonism are probably more important than $\beta$ stimulant effects in most patients other than those with overt heart failure. Similarly, the protective value of perioperative $\beta$ blockade is unarguable, but that is not to deny that other measures may improve outcome furtherparticularly measures to improve cardiac output by optimising the peripheral circulation.

These and other studies have shown that by manipulation of the circulation we can improve patient outcomes. The next step is to turn this evidence into clinical reality. That really would be clinical governance in action.

R O Feneck consultant anaesthetist

Guys and St Thomas's NHS Trust, Guy's Hospital, London SE1 9RT

rob_feneck@email.msn.com

1 Wilson J, Woods I, Fawcett J, Whall R, Dibb W, Morris C, et al. Reducing the risk of major elective surger randomised controlled trial of preoperative optimisation of oxygen therapy. BMJ 1999;7191:1099-103. (24 April.)

2 Mangano DT, Lavug EL, Wallace A, Tateo I for the Multicenter Study of Perioperative Ischemia Research Group. Effect of atenolol on mortality and cardiovascula morbidity after non-cardiac surgery. $N$ Engl I Med 1996;335:1713-20.

\section{What exactly reduces the risk?}

Editor-Wilson et al conclude that preoperative optimisation of oxygen delivery reduces the risk of major elective surgery. ${ }^{1}$ It is unfortunate, however, that 16 of the 46 control patients returned directly to a general ward after surgery. This must cast doubt on whether it is early postoperative high dependency care rather than preoperative optimisation of oxygen delivery that resulted in the difference in survival between the control and treatment groups.

Drawing comparisons between the two inotropes used in the treatment groups may also be difficult as the starting doses of the infusions were not equipotent. Dopexamine was started at one quarter the recommended starting rate of $0.5 \mu \mathrm{g} / \mathrm{kg} / \mathrm{min}^{2}{ }^{2}$

Interestingly, on average only one patient each month did not enter this study owing to a lack of high dependency or intensive care beds during the period of active patient recruitment. Our 850 acute bedded general hospital has five intensive care and two high dependency care beds, and we are interested to know the numbers of acute and critical care beds in York. Last year we refused about six or seven requests a month for admission to the intensive care unit, and we wonder what our resource implications would be if we were to adopt a programme of routine preoperative optimisation (and postoperative stay in the intensive care unit or high dependency unit) for our patients undergoing major elective surgery.

Whether it is preoperative or postoperative optimisation that makes the difference, the essential message remains the same: that high dependency or intensive care reduces the risk of major elective surgery. Adequate facilities and funding must now follow.

P E Hersch specialist registrar in anaesthesia A S Kong consultant in intensive care and anaesthesia ask4me@mail.anglianet.co.uk

R Howard-Griffi consultant in intensive care and anaesthesia

Department of Anaesthesia and Intensive Care, Ipswich Hospital NHS Trust, Ipswich IP4 5PD

1 Wilson J, Woods I, Fawcett J, Whall R, Dibb W, Morris C, et al. Reducing the risk of major elective surgery: et al. Reducing the risk of major elective surgery: f oxygen delis $B M J 1999 \cdot 318: 1099-103$. (24 A ril)

2 BMA and Royal Pharmaceutical Society of Great Britain. British national formulary. Number 37. London: BMA and

\section{Authors' reply}

EDITOR-In answer to these letters there are two areas that we would like to address: the concerns over mortality in the control group and the role of inotropes.

The United Kingdom's mortality for these high risk procedures is probably higher than many people realise. For example, a recent review of colorectal work in the north west of England showed perioperative mortality for elective procedures of $9 \% .{ }^{1}$ One reason for our control mortality of $17 \%$ is the fact that we chose to measure mortality in hospital, irrespective of the time after surgery. It is traditional to consider deaths occurring more than 28 days after surgery as somehow not being related to the operative procedure. We think that this is a fanciful notion, particularly in the elderly population.

Patients with complications that ensure that they are still in hospital 28 days postoperatively are likely to go on to have a higher than expected mortality. The two late deaths in our control group, which raised mortality from $13 \%$ to $17 \%$, both occurred in patients who had been in the intensive care unit after surgery. These patients later developed infective complications on the general ward, from which they were unable to recover. If they had not had surgery they are unlikely to have developed these problems; we would therefore argue that their deaths were indeed linked to their operations.

Suhindran makes an interesting point about anastomotic breakdown being a surgical complication. We would suggest that so called surgical morbidity is indeed influenced by haemodynamic optimisation. In a patient who is slightly hypovolaemicwhich may not be clinically apparent unless the patient is monitored adequatelycirculation to the bowel will be compromised. Consequently, oxygen delivery to the site of surgery will be inadequate, compromising healing of the anastomosis.

The doses of inotropes used in our study were small, but enough to achieve the desired oxygen delivery target and improve mortality. 
Feneck points out the contradictory treatment strategies of inotrope therapy and $\beta$ blockade and argues that manipulation of the peripheral circulation may have a further influence on outcome. The incidence of complications in the dopexamine group would suggest that this might be the case. Recent animal work suggests that the improvement in splanchnic circulation observed with dopexamine is a $\beta_{2}$ mediated effect, ${ }^{2}$ as are the anti-inflammatory effects. Dopexamine has minimal $\beta_{1}$ effects; therefore the use of cardioselective $\beta$ blockers to reduce perioperative cardiac morbidity should not, in theory, seriously compromise splanchnic flow, although this remains to be proved clinically.

Jonathan Wilson consultant jonathan@critbase.demon.co.uk

Ian Woods consultant

Department of Anaesthetics, York District Hospital, York YO31 8HE

1 Parry JM, Collins S, Mathers J, Scott NA, Woodman CBJ Influence of volume of work on the outcome of treatment for patients with colorectal cancer. Br J Surg 1999;86: $475-81$.

2 Scheeren TWL, Loer SA, Schwarte LA, Picker O, Fournell A. Role of beta-2 adrenoceptors in dopexamine-induced increases in splanchnic oxygenation in anaesthetised dogs. BrJ Anaesth 1999;82(suppl 1):A140.

\section{Changing perceptions in osteoporosis}

\section{Several risk factors are important}

EDITOR-Wilkin argues for broadening the indication for treatment of osteoporosis to "infirm older people." There are several problems with the specific case he makes but evidence nevertheless to support a move in this direction. He deduces that frequency of impact is the main risk factor for fracture. Falling is indeed a recognised risk factor, but the evidence suggests that it is just one among several predictors. ${ }^{2}$

Surprisingly, few researchers have attempted to combine their results to produce a risk score. We have identified one study that produced a score with a sensitivity of $70 \%$ and specificity of $98 \%$ on the basis of three factors-bone mineral density, body sway, and muscle strength. ${ }^{3}$ This prediction is for fractures occurring within a fairly short follow up time and probably overestimates the potential for effective intervention. Our preliminary results from a similar cohort provide support for a risk score approach over a longer period.

We suggest that there is a case for focusing on elderly people but that the approach should be based on firm evidence and involve a specific risk score rather than a nebulous concept of infirmity. Hormone replacement therapy and bisphosphonates are costly and have important side effects and should not be used indiscriminately in any age group.

C W McGrother senior lecturer in epidemiology sk29@leicester.acuk

M M K Donaldson research associate Department of Epidemiology and Public Health, University of Leicester, Leicester LE1 6TP

Competing interests: None declared.
1 Wilkin TJ. Changing perceptions in osteoporosis [with commentary by R Eastell]. BMJ 1999;318:862-4. (27 March.)

2 Eddy DM, Johnston CC, Cummings SR, Dawson-Hughe B, Lindsay R, Melton LJ III, et al. Osteoporosis: review of the evidence for prevention, diagnosis and treatment and cost-effectiveness analysis. Osteoporosis Int 1998;suppl 4: S7-80

3 Nguyen T, Sambrook P, Kelly P, Jones G, Lord S, Freund J, et al. Prediction of osteoporotic fractures by postural instability and bone density. BMJ 1993;307:1111-5.

billy and bone density. BMJ 1993;307.1111-5. 4 McGrother CW, Donaldson MMK, Clayton D, Clarke M. Development of a risk score for fracture within an elderly population. Osteoporosis Int 1998;8(suppl 3):27.

\section{Replacing bone mineral density with bone turnover is not a solution}

EDITOR-Low bone mineral density is a disease surrogate; as Eastell points out in his commentary on Wilkin's article on osteoporosis, it is unfortunate that this particular surrogate has been given the status of a true diagnosis. ${ }^{1}$ But Wilkin's suggestion of replacing bone mineral density with another surrogate, bone turnover, is not a solution to the deficiencies of bone mineral density.

An important use for a surrogate is to identify groups of high risk patients so that treatment is directed most economically at those who can benefit most. Evidence suggests that measurements of bone mineral density are rather better at risk stratification than bone markers. ${ }^{2}$ For instance, $36 \%$ of hip fractures occur among women with high bone turnover, ${ }^{2}$ who are about a quarter of the older population, while for low bone mineral density about half of hip fractures occur in a similar population fraction. ${ }^{3}$ Thus Wilkin's suggestion that treatment should be targeted at infirm people with high bone turnover would result in a greater number needed to treat for every fracture prevented than would targeting treatment in the same people on the basis of bone mineral density.

Wilkin's argument turns on the premise that bone marker levels can normalised whereas abnormally low bone mineral density can be increased only slightly. This, however, is to fall into the trap of treating a surrogate rather than the disease. Thus an "infirm" 75 year old woman who has already had Colles and vertebral fractures and whose mother and older sister have both had hip fractures but who has "normal" levels of bone markers should not be treated, because her risk factors cannot be normalised. In contrast, a woman of the same age but whose only risk factor for fracture is high bone turnover, which can be normalised, should be offered treatment even though she is almost certainly at lower risk of hip fracture than the other patient. Such a situation is as bad as treating a woman whose only risk factor for fracture is low bone mineral density but not treating a patient who has multiple other risk factors but who has bone mineral density slightly greater than $1 \mathrm{SD}$ below the premenopausal mean.

The aim of treatment should be not to normalise bone mineral density or markers of bone turnover but to reduce risk of fracture. One way forward might be to use both markers and measurements of bone mass to improve the specificity of treatment and thereby its cost effectiveness. ${ }^{2}$
David J Torgerson senior research fellow Centre for Health Economics and Department of Health Studies, University of York, York YO10 5DD

Competing interests: Dr Torgerson has been reimbursed by Johnson \& Johnson Clinical Diagnostics, which manufactures tests for markers of bone turnover, for attending internal symposiums.

1 Wilkin TJ. Changing perceptions in osteoporosis [with commentary by R Eastell]. BMJ 1999;318:862-5. (27 March.)

2 Garnero P, Hausherr E, Chapuy MC, Marcelli C, Grandjean H, Muller C, et al. Markers of bone resorption predict hip fractures in elderly women: the EPIDOS prospective study.J Bone Miner Res 1996;11:1531-8.

3 Cummings SR, Black DM, Nevitt MC, Browner W, Cauley J, Ensrud K, et al. Bone density at various sites for prediction of hip fractures. Lancet 1993;341:72-5.

\section{Markers should be used as adjunct to bone densitometry}

EDITOR-Wilkin builds a case against using bone densitometry to diagnose osteoporosis by taking out of context a point from Marshall et al's meta-analysis of how well measures of bone mineral density predict the occurrence of osteoporotic fractures. ${ }^{12}$

Marshall et al indeed concluded that "bone mineral density measurements ... cannot identify individuals who will have a fracture." But of course bone density measurements cannot identify individuals who will have a fracture. Neither do cholesterol concentrations tell who will have a heart attack or blood pressure readings tell who will have a stroke. Although these measures do not predict the future for an individual, they clearly permit identification of individuals at high (and low) risk of complications and allow interventions to be targeted at high risk groups and high risk individuals.

Marshall et al also came to an important conclusion that Wilkin chose to ignore: "[the] ability of decreases in bone mass [to predict fracture] was roughly similar to (or, for hip or spine measurements, better than) that of a 1 SD increase in blood pressure for stroke and better than a $1 \mathrm{SD}$ increase in serum cholesterol concentration for cardiovascular disease." Because the risk of fracture rises dramatically after the first fracture, ${ }^{3}$ early identification and treatment are important We believe that bone density testing is the best way to identify patients at high risk of fracture before the first fracture occurs.

Clearly, there are risk factors for fracture besides bone density. We agree that biochemical markers of bone turnover provide clinically useful information, but we use markers as an adjunct to bone densitometry and fail to see convincing evidence or logic to abandon densitometry in favour of markers.

Wilkin states that "the small increases in bone density gained during the early years of treatment with hormone replacement therapy or bisphosphonate drugs soon level off." One study showed a 10\% increase in spinal bone density with treatment with alendronate - this is not small by our standards. Our long term study of intermittent cyclical etidronate showed continued gains in spinal bone density in the sixth and seventh years of treatment. ${ }^{5}$ We believe that seeing bone density stable or increasing with treatment is a good indication that treatment is effective. 
Wilkin's arguments have several flaws. There are certainly things to be learnt to advance the field, but Wilkin is pointing us in the wrong direction.

Nelson B Watts director, osteoporosis and bone health programme

Emory Clinic, Atlanta, GA 30322, USA

nwatts@emory.edu

Paul D Miller director

Colorado Center for Bone Research, Lakewood, Colorado USA

Competing interests: Dr Watts is the president elect and Dr Miller is the immediate past president of the International Society for Clinical Densitometry. Dr Watts and Dr Miller have both received research support, honoraria for lectures, and consulting fees from several pharmaceutical companies.

1 Wilkin TJ. Changing perceptions in osteoporosis [with commentary by R Eastell]. BMJ 1999;318:862-5. (27 March.)

2 Marshall D, Johnell O, Wedel H. Meta-analysis of how well measures of bone mineral density predict occurrence of osteoporotic fractures. BMJ 1996;312:1254-9.

3 Ross PD, Davis JW, Epstein RS, Wasnich RD. Pre-existing fractures and bone mass predict vertebral fracture incidence in women. Ann Intern Med 1991;114:919-23.

4 Liberman UA, Weiss SR, Broll J, Minne HW, Quan H, Bell $\mathrm{NH}$, et al. Effect of oral alendronate on bone mineral density and the incidence of fractures in postmenopausal osteoporosis. N Engl J Med 1995;333:1437-43.

5 Miller PD, Watts NB, Licata AA, Harris ST, Genant HK, Wasnich RD, et Wasnich RD, et al. Cyclical etidronate in the treatment of years of treatment. Am J Med 1997;103:468-76.

\section{Author's reply}

EDITOR-Watts identifies a key issue relating to my article questioning the value of bone densitometry in predicting bone fracture. I quoted from Marshall et al's meta-analysis that "bone densitometry measurements cannot identify individuals who will have a fracture,"1 to which Watts points out that it nevertheless identifies risk. There are two questions of crucial interest to clinicians: how much of the risk does bone densitometry really identify, and how far can bone density predict risk of fracture 10,20 , and 30 years into the future? These questions are important because bone densitometry is expensive and response in its surrogate measure (bone density) may not reflect the improvement sought (reduction in risk of fracture).

The risk of fracture is low (though not absent) between the ages of 50 and 70 , so that the case for undertaking bone densitometry in this age group in order to prescribe an antiresorptive drug with the promise of no more than halving an already minimal risk is inherently weak. Fractures first become common after the age of 65-70, but in one of the few longer term studies with sufficient numbers Gandsell et al found only poor prediction of fracture from bone densitometry, which was poorer still in the older age group. ${ }^{2}$ De Laet et al's observations in 5814 subjects indicate that, whereas the risk of hip fracture increases 13-fold from ages 60 to 80 , the changes in bone density associated with age contribute at most 1.9. ${ }^{3}$ They conclude that "the contribution of decline in bone density to the exponential increase in risk of fracture with age is relatively small."

According to De Laet et al's study, some $85 \%$ of the age related risk of fracture in women is related to factors other than bone density, but they are not accounted for in epidemiological studies such as that of Cummings et al. ${ }^{4}$ In that study, bone densities were corrected for age by $\mathrm{Z}$ score but other age related factors that contribute to risk of fracture were not. Here lies the flaw: the age related (and possibly remediable) factors that mostly account for risk of fracture were ignored and their contribution ascribed erroneously to bone density. The fundamentally important observation of Hui et al, that the same bone density predicts an eight-fold difference in risk of fracture for people of 45 compared with those of 80 makes bone densitometry an uncertain tool. ${ }^{5}$ Osteoporotic fractures occur mostly in elderly people, and most particularly in those who are infirm. Bone density adds little.

Terence J Wilkin professor of medicine

Plymouth Postgraduate Medical School, University Medicine, Derriford Hospital, Plymouth PL6 8DH terry.wilkin@phnt.swest.nhs.uk

Competing interests: None declared.

1 Marshall D, Johnell O, Wadel H. Meta-analysis of how well measures of bone mineral density predict occurrence of osteoporotic fractures BMJ 1996:312:1254-6.

2 Gansell P Johnell O Nilsson BE Gullberg B. Predicting various fragility fractures in wo Be, Gy forea B. Preding varous fragily fractures in women by forearm bone den etry. a follow-up study. Calcif Tissue The 1993,52.348-53.

De Laet CDEH, Van Hout BA, Burger H, Hofman A, Pols
HAP. Bone density and risk of hip fracture in men and HAP. Bone density and risk of hip fracture in men
women: cross sectional analysis. BMJ 1997;315:221-5. 4 women: cross sectional analysis. BMJ 1997;315:221-5.

4 Cummings SR, Black DM, Nevitt MC, Browner W, Cauley $\mathrm{J}$, Ensrud K, et al. Bone density at variou
tion of fractures. Lancet 1993;341:72-5.

tion of fractures. Lancet 1993;341:72-5.
5 Hui SL, Slemenda CW, Johston CC Jr. Age and bone mas 5 Hui SL, Slemenda CW, Johston CC Jr. Age and bone mass
as predictors of fracture in a prospective study.J Clin Invest $1988 ; 81: 1804-9$.

\section{Why transition from alternation to randomisation in clinical trials was made}

EDITOR-It is time to put the record straight about ways of controlling selection bias when generating comparison groups in clinical trials. D'Arcy Hart has done history a great service by noting that Bradford Hill's motivation for replacing alternation with randomisation was "to better conceal the allocation schedule." This is what Guy Scadding (who, with D'Arcy Hart, is the other surviving member of the team who designed the streptomycin trial) told Mike Clarke and me when we visited him on 10 June 1999, and what Bradford Hill told William Silverman and me when we visited him on 3 April 1982.

Bradford Hill's motivation for concentrating on the concealment of the allocation schedule in the streptomycin trial seems likely to have been stimulated more than a decade earlier. A Medical Research Council trial of serum treatment for lobar pneumonia had used an (unconcealed) allocation schedule based on alternation, ${ }^{2}$ and important imbalances in the characteristics of patients in the treatment and control groups had occurred. In an unpublished critique of the study for the council Bradford Hill noted that greater effort should be taken "that the division of cases really did ensure a random selection."

As Altman and Bland recently observed, treatments allocated alternately "are in principle unbiased-being unrelated to patient characteristics-[but] problems arise from the openness of the allocation system." They might have gone on to note that similar problems can arise with allocation schedules based on random numbers unless they are concealed from those entering patients into trials: the fact that an allocation schedule has been based on random numbers provides no security against biased allocation to comparison groups.

It is regrettable that a certain mystique has grown up around randomisation. This seems to reflect unwarranted inferences about R A Fisher's influence on the design of medical research, even though the history of efforts to make fair treatment comparisons in medicine predates Fisher by centuries (see Controlled Trials from History at www.rcpe.ac.uk/cochrane).

The methodological advance made by the streptomycin trial was not so much the use of randomisation to generate the allocation schedule but rather the clear efforts made by the trial's designers to conceal the allocation schedule from those involved in entering patients in the trial. The results of the streptomycin trial would have been no less valid if the trial had used a system of alternation as a basis for the allocation schedule and-against the odds-had succeeded in concealing this from those taking decisions about eligibility and allocation of patients.

In summary, the only reason that allocation schedules based on random numbers are to be preferred to those based on strict alternation is because they are easier to conceal, not because they are any better at abolishing selection bias. This is the reason that a schedule based on random numbers was used for the streptomycin trial, and why the study is a methodological landmark. As Lock has suggested, Bradford Hill deserved to receive a Nobel prize for this immensely important contribution to the process of assessing the beneficial and harmful effects of medical care

I am indebted to Doug Altman, Joan Austoker, Mike Clarke, Philip d'Arcy Hart, Richard Doll, Stephen Lock, Irving Loudon, Guy Scadding, William Silverman and Ben Toth for checking an earlier draft of this letter.

Iain Chalmers director

Cochrane Centre, Oxford OX2 7LG

ichalmers@cochrane.co.uk

1 D'Arcy Hart P. A change in scientific approach: from alternation to randomised allocation in clinical trials in the 1940s. BMJ 1999;319:572-3. (28 August)

2 Medical Research Council Therapeutic Trials Committee.

The serum treatment of lobar pneumonia. $B M$ 1934; i:231-49.

3 Lock S. The randomised controlled trial-a British invention. In: Lawrence $\mathrm{G}$, ed. Technologies of moder medicine. London: Science Museum, 1994:81-7.

4 MRC 1487, VI: A. Bradford Hill. Serum treatment of pneumonia. 22 December 1933. Cited in: Austoker J, Bryder L. The National Institute for medical research and related activities of the MRC. In: Austoker J, Bryder L, eds. Historical perspectives on the role of the MRC. Oxford: Oxford University Press, 1989:35-57.

5 Altman DG, Bland JM. Treatment allocation in controlled trials: why randomise? BMJ 1999;318:1209.

\section{Rapid responses $\quad e B M J$ \\ Correspondence submitted electronically is available on our website www.bmj.com}

